\title{
Logistics Process Optimization and Cost
}

\section{Control}

\author{
Xiao Zhen \\ Continuous Education College \\ Shengyang Aerospace University \\ Shengyang China \\ Xiaozhen@sau.edu.cn
}

\begin{abstract}
With the advent of the global economic integration, inter-enterprise transactions gradually broken the geographical constraints, companies began to expand their own business to various regions of the core strengths of manufacturing enterprises not only in its unique product design and good user experience. Efficiency and cost of business logistics, e-commerce activities in enterprise development process plays a huge role in modern logistics management has become a new way to enterprises to reduce costs and generate profits, increase economic efficiency. Business logistics as the basic unit of the logistics operation, is the foundation of social logistics, raising the level of enterprise logistics is directly related to raising the overall level of China's logistics, will also promote the development of third-party logistics, the progress of enterprise logistics supply chain management in China application and promotion.Modern logistics plays a key role in enterprise development, if a business is not dominant in terms of logistics operation, and that he was not competitive. This paper first introduces the history of the development of the logistics, the Overview and logistics costs calculation, based on the development of today's logistics analysis of the problems in the logistics process, which leads to the topic of logistics process optimization. Finally, the Shenyang HANGDA mechanical airborne equipment company for the background, the empirical analysis of the logistics process optimization and cost control.
\end{abstract}

Keywords-Logistics management; reduce cost; the level of logistics; logistics cost, logistics process

\section{LOGISTICS PROCESS AND COST ANALYSIS}

\section{A. Logistics Developing Situation in Our Country}

He Liming, as the president of China Federation of Logistics \&Purchasing ((CFLP) and China society of Logistics claimed in "Report of 2011 Year's China Logistics development" sponsored by China Federation of Logistics \& Purchasing and China Society of Logistics on January 19th, 2011, "During the period of the 11th FiveYear Plan, our country's logistics industry effectively copes with the impact of international financial crisis. Value added of logistics industry reaches 7\% GDP. The proportion between total expense in social logistics and GDP is about 18\%", when he summarized our country's logistics development. He suggested that our country's logistics industry should basically form a modern logistics system with reasonable layout, advanced technology, energy conservation and environment protection, convenience and high efficiency, security and orderliness, as well as a certain international competitiveness to the terminal stage of "the 12th Five-Year Plan". Logistics industry should be transferred into comprehensively promoting service quality from concentrating on infrastructure. Adjustment and Revitalization Plan on Logistics Industry issued by the State Council also brings logistics industry into extensive range of 2011 year's added-value tax. Based on improving land consolidation utilization, the government should increase support, reduce road toll and potage, lower down standard of higher freeway collecting toll, lighten the burden on enterprises, broaden qualification requirements and access conditions for logistics industry. Moreover, various local governments should boost investment and give aid to logistics enterprises that conform to conditions.

Modern logistics is the foundation of national economy. Logistics activities in each field of national economy horizontally constitute in logistics industry. Logistics management is born after level of productive forces evolves to a certain extent. In other words, national economy with a certain extent is the foundation of producing logistics industry, while advanced logistics industry plays acceleration on developing national economy.

\section{B. Introduction on Logistics Process}

The so-called logistics process refers to the transfer process of commodity entity from country of origin to place of consumption, or it refers to the circulation process from country of origin to transfer location of logistics, and then to place of consumption. In order to ensure reasonable logistics links, and rapid and smooth logistics process, advanced management methods and management tools should be depended, as well as a certain basic requirements should be created, which is an optimal management on logistics process.

\section{Logistics Cost and Calculation}

Internal logistics cost refers to overall cost generated by commodities in enterprises start with raw material supply, pass through production process, and then finished products and sales in production and management operation, as well as generated waster reclamation accompanied with production and consumption process.

Logistics cost is a monetary expression of enterprises' logistics system occurs all kinds of consumes for the sake of accomplishing logistics activities, realizing the transfer of commodities in space and time. Logistics cost is the sum of all cost in each link of logistic operation chains. In essence, internal logistics cost should be the achieved cost of clients' orders. In the "Term of Logistics Technology, it 
explains logistics cost in such way: the practical situation is logistics cost by applying money to evaluate logistics activities. And size of logistics cost depends on the range of logistics activities and adoptive evaluation methods.

The fundamental purpose of manufacturing enterprises is to produce products that can meet the social demands, so as to get in return corporate benefits. In order to conduct production and operating activities, enterprises must conduct purchasing, storage, and transfer of related production factors, as well as sales of finished goods, etc. simultaneously.

Compositions of logistics cost in manufacturing enterprises mainly include the following sections:

Staff salaries, bonus and multiform subsidies, etc. in links of supply, storage, transfer and sales

Buying expenses of production materials, including transportation, premium and reasonable loss cost;

Logistics fees occurred in productive process;

Sales cost of the products, such as advertising expense, traffic expense, exhibition promotion fees and information fees;

Warehouse expenses, involving in warehouse maintenance cost and carriage expense, etc.;

Depreciation cost, maintenance cost and maintenance fees, etc. of related equipment and warehouse;

Operating expense, such as energy consumption cost, material consumption cost, depreciation cost, office allowance, travel expense, premium and labor protection fees, etc.;

Financial expense, including capital interests occupied by storage and materials;

Logistics cost occurred in recycling waste.

The size of logistics cost depends on the scope of evaluation object-logistics activity, and adoptive evaluation methods, etc. Different evaluation scope and practical evaluation methods will lead to different results of logistics cost. Here the followings are the basic steps of calculating logistics cost:

1) Clear scope of logistics

As a calculating field of cost, scope of logistics refers to the length between starting point and end point of logistics. General speaking, scope of logistics commonly includes logistics of raw materials and internal logistics, namely logistics in an extensive field from the factory to warehouse, and from warehouse to customers.

2) Confirm scope of logistics functions

Scope of logistics functions refers to regard which functions as the calculating objects of logistics cost in all kinds of logistics functions. Logistics functions involve in packaging, transportation, loading and unloading, distribution processing, intelligence information flow, and logistics management, etc. seven activities.

3) Confirm scope of calculating subjects

The scope of calculating subjects refers to the problem of listing which items into calculating objects when calculating logistics cost. In calculating subjects, it not only includes freight expense and custodian fee, etc. enterprises'external expenditure, but also involves in labor cost, depreciation cost, repair charge and fuel fees, etc. internal expenditure. Which expenditure items are listed into calculating subjects of cost will have impacts on the size of logistics cost.

\section{Overview of Activity-Based Costing}

Distribution of activity-based costing in indirect costs will be more accurate than traditional methods. It traces back to the origin of expenditure, instead of distributing cost by direct relationships with production. Its basic logic is: all kinds of resource costs drive the occurrence of costs. Therefore, the number of various products should depend on the consumption on various activities and check costs based on it. Here the cost management will be equipped with the greater accuracy. Principles of activity-based costing can be concluded as the following 4 points:

Enlargement of product costs scope and traceability theory of cost

Activity-based costing thinks any activity that contributes to add value should be involved in the cost of products and services. However, its attributive objects of cost are not products, but the operations that relate to products, including production cost, technical cost, logistics lost, information cost, selling cost, marketing cost, service cost and delivery cost, financial administrative cost, and general administrative cost, which are collectively known as supporting costs.

Recognition on cost behavior: Kaplan and Cooper divide variable cost into short-term variable cost and longterm variable cost. The former includes direct material cost and direct labor costs, while the latter refers to the cost that will change with business volume in the long term.

Theory of cost driving factors: Activity-based costing thinks that most of costs are variable. Therefore, it is hard to find the causes of forming these cost and variations.

Generally speaking, logistics operation costing needs to pass through the following several stages: analyze and confirm resources, analyze and confirm operation, confirm resource driver, establish activity cost pool, confirm activity driver, distribute cost to objects of cost, as shown in the following figure: 


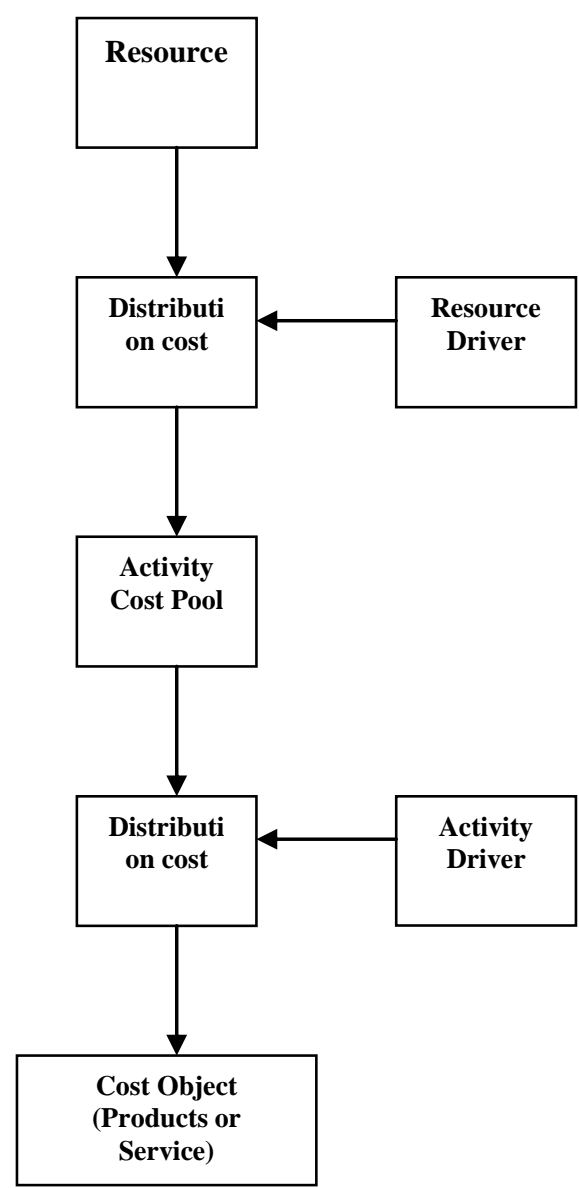

Figure 1. Calculating Stages of Activity-Based Costing

\section{LOGISTICS PROCESS OPTIMIZATION}

\section{A. Overview of Logistics Process Optimization}

Logistics system adopted optimal management methods can be firstly conducted within each single activity in the logistics process, such as, optimal transport planning on transport links, inventory management on confirming its reasonable inventory ration, optimal distribution lines and distribution proportions on distribution operation, etc. Finally, it can conduct stimulation on the entire logistics system, adopt the most effective quantitative analysis to organize logistics system and make it become rationalization.

Optimal transport planning: Under the circumstances of unit freight from the enterprise to consumption places, load distance, production capacity and consumption of each enterprise have been confirmed, and linear programming technology can be used for solving organizational problem of transportation. If the production of enterprises are changed, and operating cost function is nonlinear, then it can use nonlinear programming to solve. Transportation problems that belong to linear programming types generally can be applied with simplex method and table dispatching method.

Confirm reasonable inventory ration: Reasonable inventory not only is the premise of providing high-quality service for users, but also is the requirement for marketing profits. We must regard $100 \%$ service rate of users at the utmost as the primary employment objective. In this context, to strive for favorable profits and lower market risk. All of these are established under the foundation of reasonable inventory.

Optimal distribution lines and distribution proportion: with the complication of distributions, optimization of distribution lines generally needs to be combined with mathematical methods and computing solutions to formulate reasonable delivery schemes. At present, one of comparatively mature methods of optimizing delivery schemes is saving method, namely saving algorithm.

Through the management optimization on every detail in logistics process, optimization between each system and each element in logistics process harmoniously operates, and it can adapt and promote the development of commodity economy, so as to obtain the best economic benefits. In certain condition, the fastest running speed, lowest labor expense, flow at most, best liquid and optimal services, the best efficacy and effects are provided to logistics. Moreover, combination of dialogue factors is equipped with normative and comprehensive reasonable symbols.

Rationalized pattern of logistics from the perspective of manufacturing enterprises

When enterprises work on logistics activities, they generally depend on storage, professional organizations of transportation, or they will store and transport by themselves. When manufacturing enterprises entrust professional storage and transportation of logistics to carry out logistics activities, they must overall inspect the purchasing and sales status of the enterprise. In order to make logistics rationalized, cost of every specific logistics activity should be the minimum. Logistics should adapt to the requirements of production and sales development. Commodities with excellent quality and appropriate quantity should be fed to the buyer with thoughtful services and the smallest cost at proper site and in right time.

Reasonable pattern of Logistics from the perspective of sales

Enterprises take advantages of their storage and transportation or make use of professional Storage and Transportation Company. When logistics center organizes logistics to realize sales of commodities, enterprises are in the status of marketing organization logistics. The critical thing for marketing is to conduct research, select target market, and formulate reasonable sales strategy. In logistics process, sales strategy often brings in decisive influences on logistics conditions.

\section{B. Implementation of Logistics Process Optimization and Cost Control}

With the advent of global economic integration, transaction among enterprises also gradually breaks the limitation of regions. Enterprises start to expand their businesses to each region. The core advantage of manufacturing enterprises not only lies in its unique 
product design and favorable user experience. Efficiency and cost of internal logistics also plays tremendous roles on developing enterprises and carrying out E-commerce activities. Modern logistics management has become a new approach to reduce enterprises' cost, create profits and improve economic returns. As basic unit, internal logistics is the foundation of social logistics. The increase of internal logistics has the direct bearing on improving our country's integral level of logistics, as well as driving the logistics development of the third party. An improvement upon internal logistics will make for application and promotion of supply chain management in our country. From the development perspective of domestic internal logistics, construction of logistics infrastructure is imperfection with behindhand management tools and informationalized level, as well as shortage of competitive ideas.

\section{CONCLUSION}

Our country's logistics industry in the future will get into a higher developmental stage and present some new development tendency and features. With the rapid and stable development of national economy, scale of logistics industry will continue to rapidly expand, as well as adapt to adjustment of economic structure and industrial distribution. Concentration ration of logistics industry will be further promoted. With the continuous expansion of logistics market, division of labor in logistics industry will be increasingly refined. Moreover, institutional environment of developing logistics industry will gradually become standardized. In addition, market order and environment conditions are also further optimized.

With the advent of global economic integration, transaction among enterprises also gradually breaks the limitation of regions. Enterprises start to expand their businesses to each region. The core advantage of manufacturing enterprises not only lies in its unique product design and favorable user experience. Efficiency and cost of internal logistics also plays tremendous roles on developing enterprises and carrying out E-commerce activities. Modern logistics management has become a new approach to reduce enterprises' cost, create profits and improve economic returns. As basic unit, internal logistics is the foundation of social logistics. The increase of internal logistics has the direct bearing on improving our country's integral level of logistics, as well as driving the logistics development of the third party. An improvement upon internal logistics will make for application and promotion of supply chain management in our country. From the development perspective of domestic internal logistics, construction of logistics infrastructure is imperfection with behindhand management tools and informationalized level, as well as shortage of competitive ideas.

\section{REFERENCE}

[1] Jiang Meng, "Internal Logistics Cost Control under the Circumstance of Supply Chain", Shougang Group Mining Company, 2011

[2] Zheng Junping, "Logistics Cost Control of Internal Logistics", Putian University Affiliated Hospital, 2011.

[3] Mei Yuan, "Current Management Situation and Countermeasure on Our country's Logistics", Wuhan Commerce Vocational College, 2011.

[4] Li Weiwei, Zhou Rusheng, "Logistics Process Monitoring and Visual Management System Analysis \& Design Based on RFID”, Ministry of Transport Highway Academy of Science, 2010.

[5] Huang Lu, "Brief Introduction on Cost Advantage of How to Forge Entire Logistics Process", 2011.

[6] Cong Peihua, "Influence Factors and Control Strategies of Internal Logistics Cost”, Jiangxi Finance College, 2011.

[7] Duan Qingsha, "Cost Control Research in Internal Logistics Process", 2011.

[8] Shi Enjing, Lu Wei, "Discussion on How to Reduce Our Country's Logistics Cost", Hebei Transport \& Vocational Technical Institute, 2011.

[9] Li Tengwei, Si Lin, “Analysis on Our Country's Internal Logistics Cost Management”, 2010. 